\title{
Field studies of hearing in teleost fish
}

\author{
C. J. CHAPMAN \\ Marine Laboratory; Aberdeen, Scotland
}

\begin{abstract}
KURZFASSUNG: Freilandversuche über das Hörvermögen bei Teleostiern. Versuche über das Hörvermögen verschiedener mariner Fische - des Schellfischs (Melanogrammus aeglefinus), des Pollacks (Pollachius pollachius), des Kabeljaus (Gadus morbua) und des Lengs (Molva molva) - wurden im Biotop, und zwar in $20 \mathrm{~m}$ Tiefe bei Loch Torridon (Schottland) durchgeführt. Die Reaktionen der Fische wurden mit Hilfe einer besonderen Dressurtechnik getestet, wobei dem Tonreiz ein leichter elektrischer Schock folgte; wurde das akustische Signal wahrgenommen, traten Veränderungen im Elektrokardiogramm der Fische auf. Alle 4 Arten wiesen ein ähnliches Hörvermögen auf. Im Niederfrequenzbereich von etwa $60-300 \mathrm{~Hz}$ wurde die hödhste Empfindlichkeit registriert. Bei höheren Frequenzen stellte sich eine Verminderung der Empfindlichkeit ein; nur Molva molva konnte zuverlässig auf einen Ton von $550 \mathrm{~Hz} \mathrm{ab-}$ gerichtet werden. Im Bereich niederer Frequenzen waren alle Fische äußerst empfindlich; es ergaben sich Hinweise, daß die Hörschwellen vom Eigenrauschen des Meeres maskiert wurden. Dies wurde durch Versuche bestätigt, bei denen die Intensität des Eigenrauschens vergrößert wurde, die Mithörschwellen aber in konstantem Abstand zum Störpegel blieben. Ferner wurde festgestellt, daß die Verdeckung reiner Töne wesentlich vermindert wurde, wenn Ton und Störpegel aus verschiedenen Richtungen (im rechten Winkel zueinander) abgestrahlt wurden. Daraus ist $z u$ schließen, daß die Fähigkeit, die Richtung der Schallquellen zu unterscheiden, gut entwickelt sein dürfte.
\end{abstract}

\section{INTRODUCTION}

Numerous hearing studies have been carried out on a great number of fish species, representative of different families and habitats (see recent reviews by TAvolgA 1965,1972 ). These studies reveal that the majority of fish are sensitive to low frequency sounds up to about $2 \mathrm{kHz}$ although hearing in some groups (such as the freshwater Ostariophysi) does extend up to about $5 \mathrm{kHz}$. There is a great deal of variation in the sensitivity of fish to these sounds. This variability is apparent, not only between different species, but also when the thresholds obtained by different authors for the same species are compared. One of the chief reasons for this variation lies in the diverse methods that are employed in hearing studies on fish, of which the most significant factor is undoubtedly the acoustic conditions under which the experiments were conducted.

The majority of published reports are based on pure tone threshold measurements obtained in small aquarium tanks which are totally inadequate for this purpose. Griffin (1950), Parvulescu $(1964,1967)$ and Chapman \& Hawkins (1973) have 
stressed the deficiencies of small thin-walled aquariums where the water-air boundaries form almost perfect reflectors of sound. On reflection there is a change in the relationship between the two fundamental parameters of sound, the sound pressure and the particle velocity or displacement. For a sound travelling in an infinite medium the ratio between these two parameters is equal to the acoustic impedance of the medium. Water and air have very different acoustic properties (the acoustic impedance for sea water is about 4000 times the value for air) and it has been suggested that the acoustic impedance of a small thin-walled container of water approaches that of the surrounding air (Parvulescu 1967, Jacobs \& Tavolga 1967). This means that a small sound pressure generated within the tank will produce very large particle displacements whereas under free-field conditions in the sea the displacement amplitude for the same sound pressure would be very small indeed. Problems will obviously arise if a small aquarium is used to examine the hearing of fish which are potentially sensitive to both sound pressure and particle displacement (Poggendorf 1952, Harris \& van Bergeijk 1962, Chapman \& Hawkins 1973). Hearing sensitivity is usually expressed in terms of sound pressure, which is easily measured using conventional hydrophones, but if the fish is actually responding to the particle displacement (which is highly likely in aquaria because of the large displacement amplitudes involved) the measure of the animal's response in terms of the sound pressure is meaningless. One way around this difficulty would be to measure the particle displacement or velocity. Several attempts have recently been made to construct, from conventional accelerometers, transducers which can be used to measure these parameters, but these instruments are not generally available to biologists.

The solution adopted by the present author has been to investigate the hearing of marine fish on an acoustic range in their natural environment where the fish and sound transducers are well away from reflecting boundaries. Under these conditions the measurement of sound pressure can be used to specify all the other parameters of the sound by means of the appropriate wave equations. Using this field approach a detailed study was made of hearing in the cod, Gadus morbua L., using a cardiac conditioning technique (CHAPMAN \& HawkINs $1970 \mathrm{a}, \mathrm{b}, 1973$ ). The results of this work showed that cod were so sensitive to low frequency sounds that their hearing was affected by the level of ambient sea noise. The present paper extends this observation to three other members of the family Gadidae: the haddock, Melanogrammus aeglefinus (L.), the pollack or lythe, Pollacbius pollachius (L.) and the ling, Molva molva (L.). In addition, some experiments are described which suggest that haddock and cod are able to discriminate between sounds from different directions.

In many respects these four species have rather different habits, but they all have in common the ability to produce sounds during various aspects of their social behaviour. Characteristic low-frequency pulsed sounds have been recorded from cod (BRAwN 1961), haddock (Hawkins \& ChapMan 1966, Hawkins et al. 1967) and pollack (CHAPMAN unpublished). Although sounds from ling have not been recorded, this species possesses the paired swimbladder "drumming" muscles so characteristic of other sound-producing members within the Gadidae (HAwrins unpublished). 


\section{METHODS}

\section{Apparatus}

The acoustic range was set up at a depth of $21 \mathrm{~m}$ in upper Loch Torridon, Wester Ross, Scotland, in 1968 (Admiralty Chart No. 2638, latitude $57^{\circ} 32.29^{\prime} \mathrm{N}$, longitude $05^{\circ} 34.33^{\prime} \mathrm{W}$ ). It consists of a framework constructed from rigid PVC tubing ("Durapipe", type upvc, 38 and $50 \mathrm{~mm}$ in diameter) perforated with holes to admit water and release air. The material has similar acoustic properties to sea water. The top of the

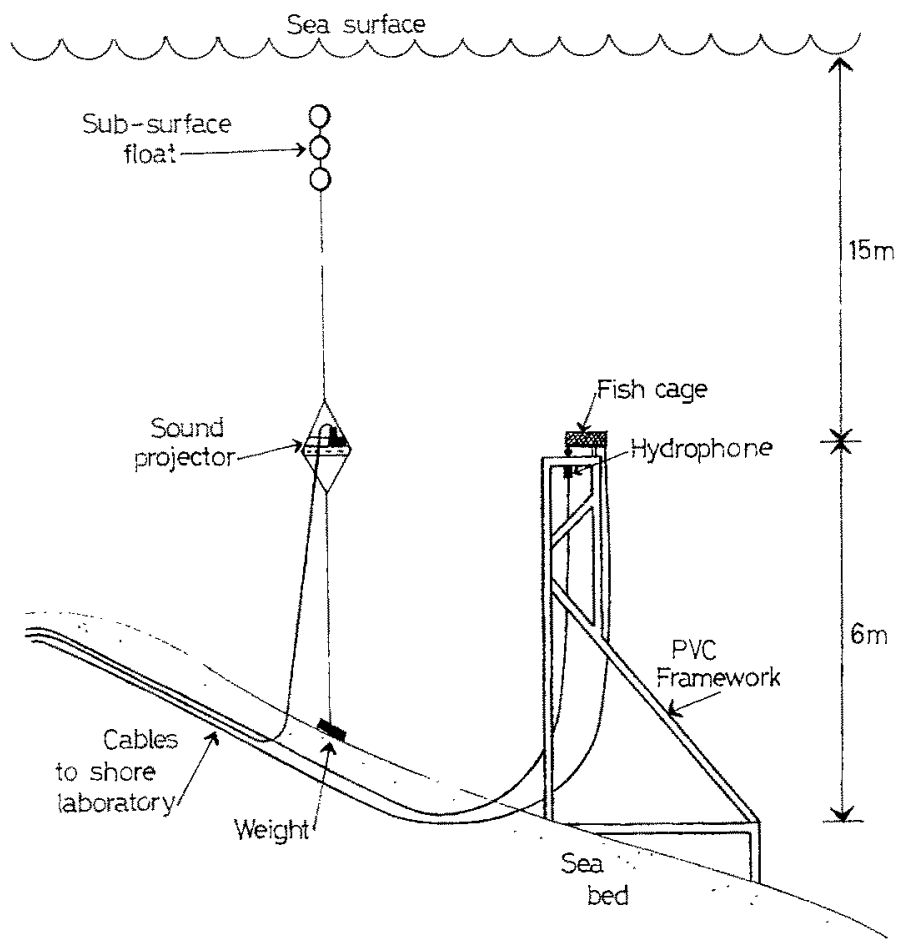

Fig. 1: Diagram of the acoustic range in Loch Torridon. Note that for clarity the height of the framework above the sea bed is exaggerated relative to the depth from the surface

framework was $6 \mathrm{~m}$ above the sea bed and $15 \mathrm{~m}$ below the surface (Fig. 1). Two calibrated hydrophones were mounted at the top of the framework equidistant from a sound projector (Dyna-Empire Inc. type J9) which was supported on an aluminium platform anchored to the sea bed and buoyed up by subsurface floats. The distance of the sound projector from the hydrophone varied between 1 and $3 \mathrm{~m}$. In later experiments, described below, three $\mathrm{J} 9$ sound projectors were used.

The fish to be tested was anaesthetised in 1:15 000 solution of MS-222 (Sandoz) in sea water and a small silver or stainless steel wire electrode was inserted ventrally to detect the electrocardiogram. The fish was then placed in a tubular cage of plastic 
netting lined with thin opaque PVC sheet. The cage was fitted with a pair of stainless steel mesh electrodes to permit the application of a mild electric shock to the tail of the fish. The caged fish was then taken to the underwater site by divers and mounted on top of the framework about $10 \mathrm{~cm}$ above the hydrophones. The ECG and shock electrodes were joined to cables via underwater connectors (Electro-Oceanics). The cables from the underwater site led to a laboratory hut ashore where the conditioning experiments were conducted.

The heart beats from the fish were filtered and amplified by a low noise preamplifier (Tektronix, type 122) and recorded on a storage oscilloscope and ultra-violet recording oscillograph. Sound signals, monitored on the hydrophones, were amplified

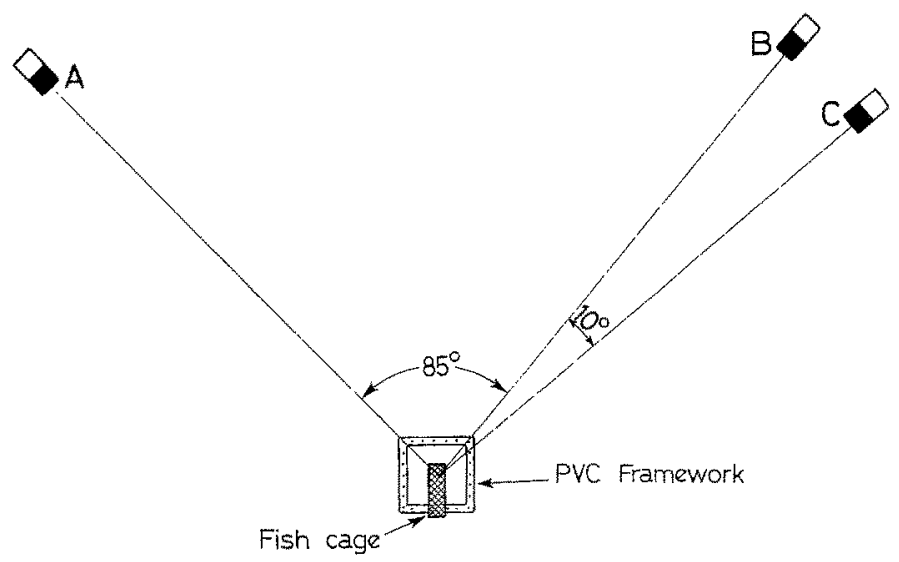

Fig. 2: Plan showing the top of the framework and the arrangement of three sound projectors used in the directional masking experiments

and filtered by a low noise amplifier (Brookdeal 450) and then measured on a narrow band frequency analyser and level recorder (BRüEL \& KJAER, type 2107/2305). The same filter system was used to obtain frequency spectra of ambient sea noise and of random noise transmitted through the sound projector. All noise measurements made with this filter were converted to spectrum levels by applying a correction for the filter bandwidth. Noise level and threshold measurements in this paper are given in decibels relative to a sound pressure of 1 microbar" (i.e. $\mathrm{dB} / \mu \mathrm{bar}$ ).

Pure tone sound stimuli were generated by a beat frequency oscillator (BRÜEL \& KJAER, type 1022) connected via an attenuator and power amplifier to the sound projector. The onset and duration of the tone stimulus was controlled by a gating circuit with a slow rise time of $0.3 \mathrm{sec}$, to produce a transient-free pulse lasting about $8 \mathrm{sec}$. At the end of this period a 12 volt DC shock pulse of $0.2 \mathrm{sec}$ duration was delivered to the shock electrodes.

In some experiments, the background noise level was raised artificially by transmitting random noise through the sound projector. The noise had a bandwidth of units.

* Note that 1 microbar is equal to $10^{-1}$ Newton per square metre in the MKS system of 
$300 \mathrm{~Hz}$ (at the $3 \mathrm{~dB}$ down points) which could be centred at the same frequency as the tone stimulus. Outside the pass band the noise was attenuated by $27 \mathrm{~dB}$ per octave. When the pure tone stimulus and the noise were transmitted through the same sound projector, the two signals were combined by means of an adding circuit. In some cases the relative directions of the masking noise and the tone were varied by using separate $\mathrm{J} 9$ sound projectors, arranged as shown in Figure 2. Each projector was placed $3 \mathrm{~m}$ from the fish and their frequency transmission characteristics were virtually the same. The angular separations between the sound sources A-B, B-C were $85^{\circ}$ and $10^{\circ}$ respectively.

\section{Experimental animals and conditioning procedure}

Hearing studies were carried out on 9 haddock (length, 23-38 cm), 2 pollack (26 and $28 \mathrm{~cm}), 3 \operatorname{cod}(29-38 \mathrm{~cm})$ and 1 specimen of ling (55 cm in length). With the exception of the ling, all the fish were captured on baited fishing lines in the shallow parts of Loch Torridon, less than $10 \mathrm{~m}$ in depth. Ling proved to be very difficult to obtain in good condition since they occur in relatively deep water. The single specimen was caught at a depth of $25 \mathrm{~m}$ in a baited lobster creel and it was brought to the surface slowly over a period of several hours to avoid swimbladder rupture. The fish were maintained in an aquarium ashore until required.

After transfer to the underwater site, the fish were left undisturbed for at least 24 hours to allow the heart rate to settle down before conditioning commenced. The tone stimulus was presented for the duration of four normal heart beats (about $8 \mathrm{sec}$ ) followed by the electric shock. The conditioned response consisted of a delay in one or more heart beats following the onset of the tone but before receiving the shock (see Fig. 10). Full conditioning was considered to have occurred when five consecutive trials had yielded positive responses and a threshold for the response was then determined by gradually lowering the sound level. After each positive response the sound level was lowered by $3 \mathrm{~dB}$, and conversely, after a negative response the sound level was raised by $3 \mathrm{~dB}$. The $50 \%$ threshold level was estimated using the method of Drxon (1965). Examples of threshold determination curves are given in Figures 6 and 9. Further details of the techniques employed are given by CHapman \& Hawrins (1973).

\section{RESULTS}

Specimens of all four species readily responded to low frequency sounds and in some cases, positive responses were given on the first trial. Full conditioning was usually achieved within 10 trials. In addition to cardiac responses, all the haddock produced trains of pulsed sound characteristic of this species. The sounds were produced first in response to the electric shock alone and then at the onset of the tone once conditioning was established. Sound production did not occur during conditioning of any of the other species. The audiogram for the cod will be published in another paper (CHAPMAN \& HAWKINS 1973). 


\section{The audiogram for the haddock}

The mean thresholds obtained from 9 specimens of haddock are plotted in terms of sound pressure in Figure 3. The standard deviation for each mean is given in Table 1. The haddock were most sensitive to frequencies between 110 and $310 \mathrm{~Hz}$ where the thresholds varied between -15 and $-20 \mathrm{~dB} / \mu$ bar. They showed a gradual decline in sensitivity below $110 \mathrm{~Hz}$ and a sharp drop in sensitivity above $310 \mathrm{~Hz}$. The highest frequency at which reliable thresholds could be obtained was $470 \mathrm{~Hz}$. Considerable variation in the data is apparent at all frequencies tested. Much of this variation resulted from changes in the level of sea noise. The variability due to this factor obscured any differences there may have been in the thresholds obtained at different sound source distances $(1.0,1.7$ and $3.0 \mathrm{~m})$. The relationship between the thresholds and the ambient noise level is suggested in Figure 1 by the similarity in the shape of the threshold and noise spectrum curves at frequencies between 40 and $380 \mathrm{~Hz}$.

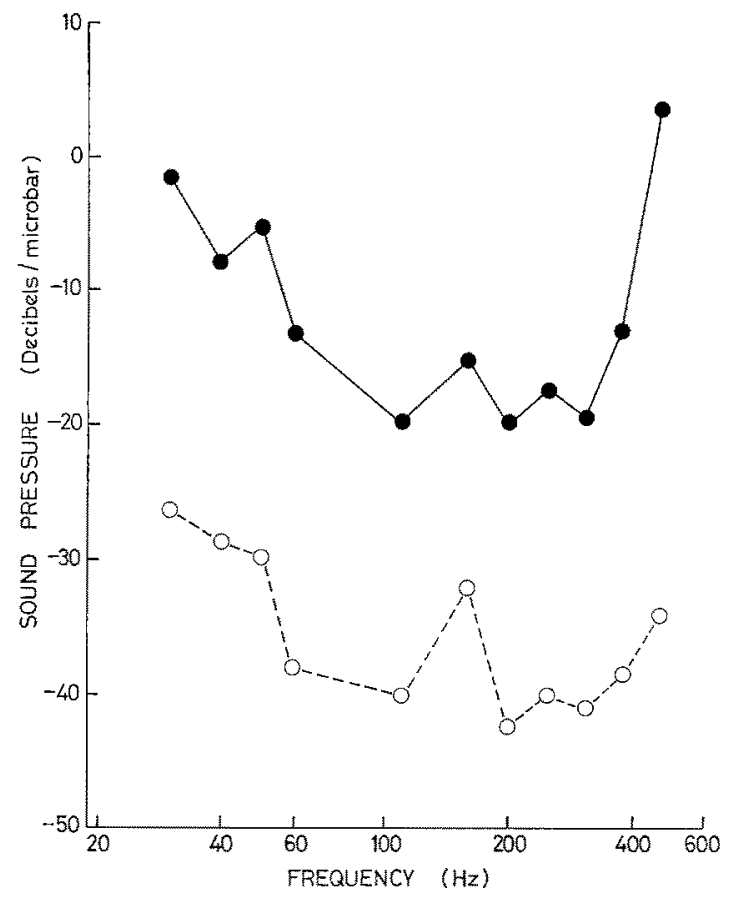

Fig. 3: Audiogram for the haddock in relation to the spectrum level of sea noise. Mean threshold (O); mean spectrum level $(O)$. Note high threshold at $160 \mathrm{~Hz}$ corresponding to the elevated noise level at this frequency

The audiogram for the pollack

The thresholds obtained from two specimens of pollack are summarised in Table 2. In Figure 4 the threshold curve has been fitted to the lowest thresholds at each 
Table 1

Summary of auditory thresholds for 9 specimens of haddock, Melanogrammus aeglefinus, and data on the spectrum level of sea noise. S.D. = Standard deviation

\begin{tabular}{|c|c|c|c|c|c|c|c|}
\hline \multirow{2}{*}{$\begin{array}{l}\text { Frequency } \\
(\mathrm{Hz})\end{array}$} & \multirow{2}{*}{$\begin{array}{l}\text { Number of } \\
\text { deter- } \\
\text { minations }\end{array}$} & \multicolumn{2}{|c|}{$\begin{array}{l}\text { Threshold } \\
\text { (dB/ } / \mu \text { bar) }\end{array}$} & \multicolumn{2}{|c|}{$\begin{array}{l}\text { Spectrum } \\
\text { level } \\
\text { (dB/ } / \mu \text { bar) }\end{array}$} & \multicolumn{2}{|c|}{$\begin{array}{l}\text { Threshold: } \\
\text { noise ratio } \\
\text { (dB) }\end{array}$} \\
\hline & & Mean & S.D. & Mean & S.D. & Mean & S.D. \\
\hline 30 & 3 & -1.6 & 9.7 & -26.3 & 0.6 & 24.7 & 10.3 \\
\hline 40 & 3 & -7.8 & 2.3 & -28.6 & 2.0 & 20.8 & 2.0 \\
\hline 50 & 3 & -5.1 & 3.4 & -29.7 & 1.5 & 24.6 & 3.2 \\
\hline 60 & 4 & -12.9 & 4.1 & -37.9 & 2.1 & 25.1 & 3.3 \\
\hline 110 & 8 & -19.6 & 4.5 & -40.1 & 4.8 & 20.5 & 5.4 \\
\hline 160 & 5 & -15.1 & 7.3 & -32.1 & 7.2 & 17.0 & 5.0 \\
\hline 200 & 6 & -19.7 & 3.9 & -42.5 & 3.4 & 22.8 & 3.2 \\
\hline 250 & 3 & -17.3 & 3.5 & -40.1 & 4.0 & 22.8 & 0.6 \\
\hline 310 & 3 & -19.3 & 5.4 & -41.0 & 8.3 & 21.7 & 3.0 \\
\hline 380 & 4 & -12.7 & 8.9 & -38.5 & 13.5 & 25.8 & 9.4 \\
\hline 470 & 3 & $+\quad 3.7$ & 2.6 & -34.1 & 3.3 & 37.9 & 2.7 \\
\hline
\end{tabular}



Fig. 4: Audiogram for the pollack in relation to the spectrum level of sea noise. The upper curve has been fitted to the thresholds ( obtained in the low noise levels shown by the lower curve $(O)$. The thresholds marked by arrows were masked by the corresponding high noise levels shown above the lower curve



Fig. 5: Audiogram for a single specimen of the ling in relation to the spectrum level of sea noise. The upper curve has been fitted to the thresholds (O) obtained in low noise levels shown by the lower curve (O). Note correspondence between masked thresholds (marked by arrows) and higher noise data 
Table 2

Auditory threshold determinations for 2 specimens of pollack, Pollachius pollachius, and data on the spectrum level of sea noise. The distance of the sound source for each determination was $1.0 \mathrm{~m}$. S.E. is the standard error of the threshold estimate which is $\sigma(2 / \mathrm{N})^{1 / 2}$, where $\sigma$ is the step size (i.e. $3 \mathrm{~dB}$ ) and $\mathrm{N}$ is the number of trials used in the threshold determinations

\begin{tabular}{|cccccc|}
\hline $\begin{array}{c}\text { Frequency } \\
(\mathrm{Hz})\end{array}$ & $\begin{array}{c}\text { Fish } \\
\text { number }\end{array}$ & $\begin{array}{c}\text { Threshold } \\
(\mathrm{dB} / \mu \text { bar })\end{array}$ & S.E. & $\begin{array}{c}\text { Spectrum } \\
\text { level } \\
(\mathrm{dB} / \mu \text { bar })\end{array}$ & $\begin{array}{c}\text { Threshold: } \\
\text { noise ratio } \\
(\mathrm{dB})\end{array}$ \\
\hline 40 & TP 1 & -12.6 & 1.13 & -33.2 & 20.6 \\
60 & TP 1 & -16.9 & 1.18 & -36.5 & 19.6 \\
110 & TP 4 & -21.1 & 1.10 & -34.7 & 13.6 \\
& TP 1 & -22.4 & 1.22 & -44.0 & 21.6 \\
160 & TP 4 & -11.5 & 1.22 & -33.6 & 22.1 \\
& TP 1 & -23.4 & 1.18 & -45.3 & 21.9 \\
& TP 4 & -23.9 & 1.22 & -38.8 & 14.9 \\
310 & TP 1 & -10.7 & 1.06 & -29.3 & 18.6 \\
470 & TP 1 & -18.8 & 1.10 & -40.8 & 22.0 \\
& TP 4 & -17.9 & 1.22 & -47.1 & 29.2 \\
& TP 1 & -9.1 & 1.10 & -31.9 & 22.8 \\
& & & 1.10 & -38.6 & 46.3 \\
\hline
\end{tabular}

frequency. These thresholds were obtained on occasions when the level of ambient sea noise was low (represented by the lower curve in Fig. 4). It was clear that the higher thresholds (marked by arrows in Fig. 4) were masked by high levels of sea noise.

The audiogram for the pollack is very similar to that for the haddock. They were most sensitive to frequencies between 100 and $200 \mathrm{~Hz}$ with thresholds between -22 and $-24 \mathrm{~dB} / \mu$ bar. The curve rose steeply at high frequencies and the threshold at $470 \mathrm{~Hz}$ was about $+8 \mathrm{~dB} / \mu$ bar.

\section{The audiogram for the ling}

Table 3 gives a summary of the threshold determinations for the ling. The overall shape of the threshold curve in Figure 5 is similar to the audiograms for haddock and

Table 3

Auditory threshold determinations for a single specimen of ling, Molva molva and data on ambient sea noise. The sound source distance was $1.35 \mathrm{~m}$

\begin{tabular}{|ccccc|}
\hline $\begin{array}{c}\text { Frequency } \\
(\mathrm{Hz})\end{array}$ & $\begin{array}{c}\text { Threshold } \\
(\mathrm{dB} / \mu \mathrm{b} \text { bar })\end{array}$ & S.E. & $\begin{array}{c}\text { Spectrum } \\
\text { level } \\
(\mathrm{dB} / \mu \text { bar })\end{array}$ & $\begin{array}{c}\text { Threshold: } \\
\text { noise ratio } \\
(\mathrm{dB})\end{array}$ \\
\hline 40 & -13.6 & 1.13 & -31.0 & 17.4 \\
60 & -16.5 & 1.28 & -41.0 & 24.5 \\
160 & -10.4 & 1.18 & -34.0 & 23.6 \\
200 & -19.2 & 1.34 & -44.0 & 24.8 \\
310 & -7.8 & 0.99 & -33.0 & 25.2 \\
380 & -10.2 & 1.13 & -43.3 & 33.1 \\
470 & -2.0 & 1.13 & -44.0 & 42.0 \\
550 & +9.0 & 1.13 & -45.6 & 54.6 \\
\hline
\end{tabular}


pollack. The ling was most sensitive to a frequency of $200 \mathrm{~Hz}$ where the threshold was $-19.2 \mathrm{~dB} / \mu \mathrm{bar}$. The thresholds increased sharply at higher frequencies; at $550 \mathrm{~Hz}$, the threshold was $+9 \mathrm{~dB} / \mu$ bar. The elevated thresholds at 160 and $310 \mathrm{~Hz}$ (marked by arrows in Fig. 5) were obtained in high ambient noise levels.

\section{The effect of sea noise}

During the course of some threshold determinations, it was found that changes in the ambient sea noise level in Loch Torridon were accompanied by corresponding shifts in the threshold levels. This is illustrated in Figure 6, which shows three series of

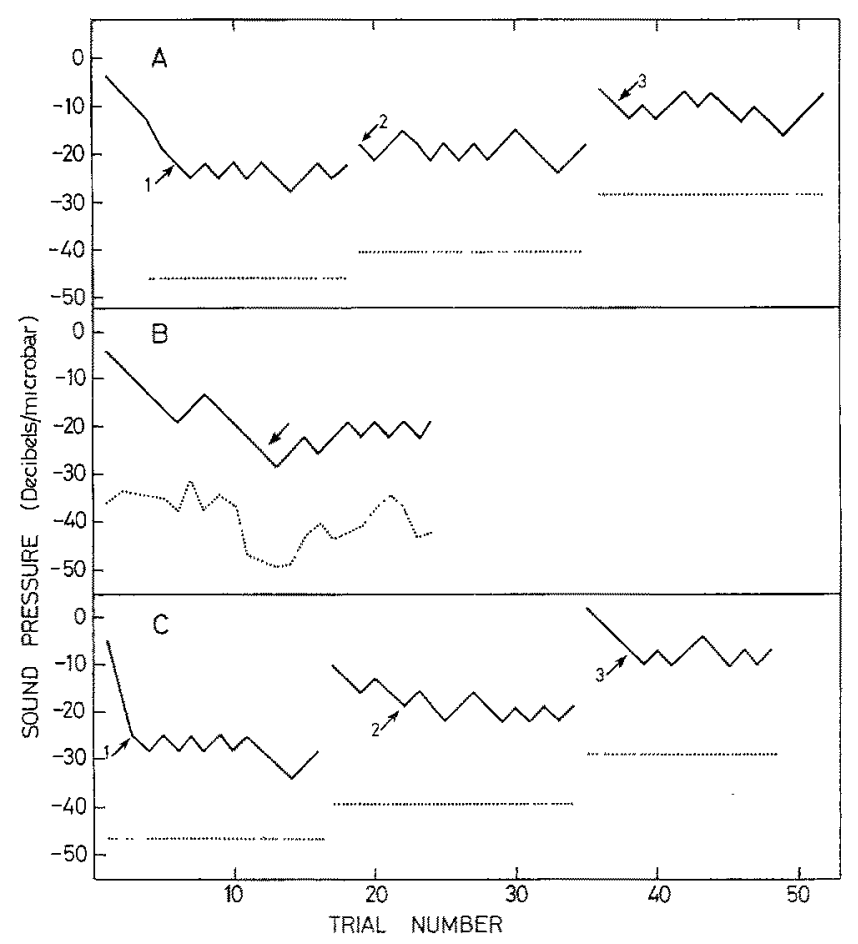

Fig. 6: Threshold determination curves (solid lines) in different levels of ambient noise (dotted lines). $A$ sequence of curves for the pollack, at a tone frequency $160 \mathrm{~Hz}$; the thresholds, $1-3$ were $21.9,22.0$ and $18.6 \mathrm{~dB}$ above the spectrum level of sea noise. $B$ threshold determination for a haddock at $380 \mathrm{~Hz}$ in fluctuating sea noise. $C$ sequence of threshold curves at $200 \mathrm{~Hz}$ for haddock; thresholds 1,2 in sea noise; threshold 3 in transmitted random noise; the threshold: noise ratios were $19.8,20.3$ and $21.3 \mathrm{~dB}$. The arrows indicate the point where the threshold calculation was begun

threshold determinations in different noise levels. In some cases, gusts of very strong winds (squalls) resulted in large fluctuations in noise level which made threshold determination very difficult (Fig. $6 \mathrm{~B}$ ). The masking effect of sea noise was confirmed when the noise level was raised artificially by transmitting random noise through the 


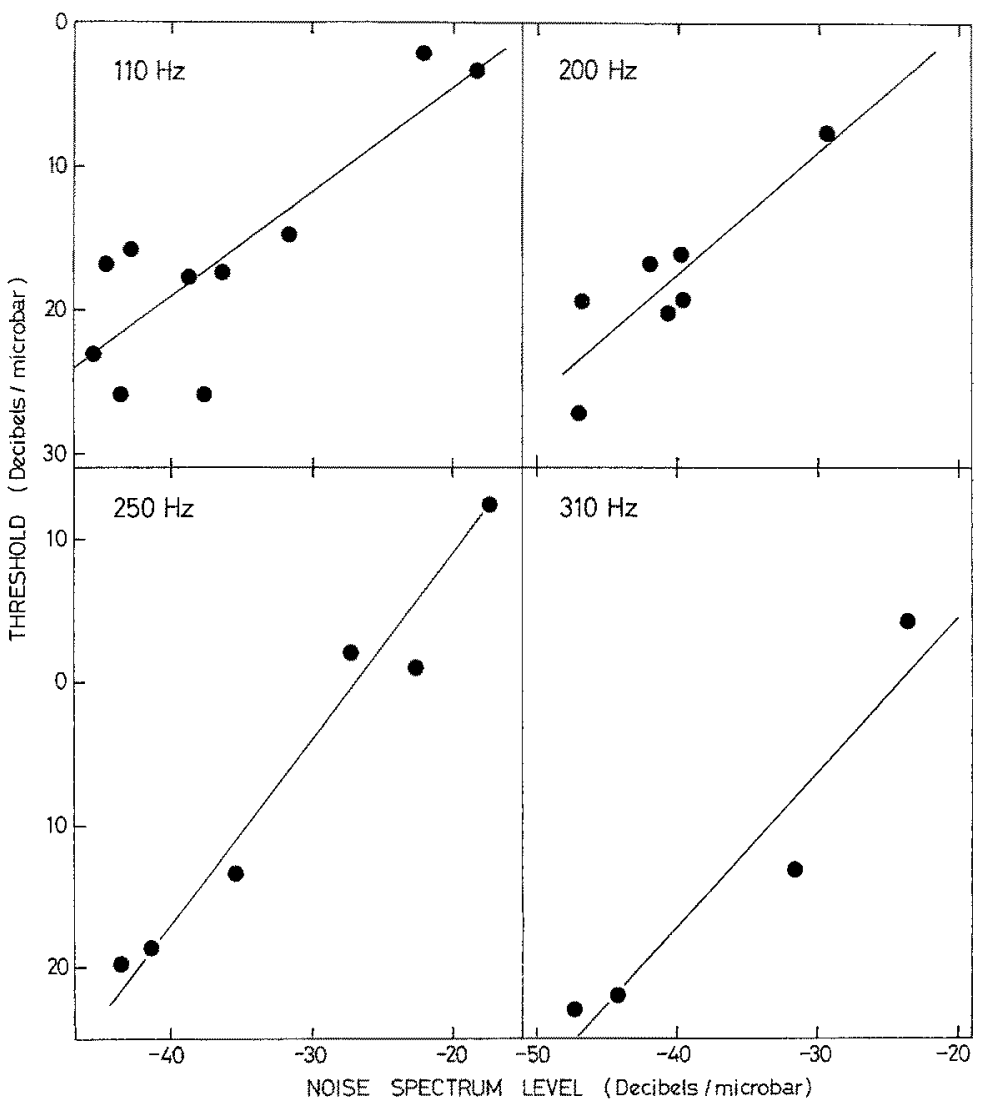

Fig. 7: Hearing data for haddock showing the relationship between the thresholds and the spectrum level of ambient noise at four frequencies

sound projector. As the noise level increased the threshold maintained a constant ratio to the spectrum level of the noise. In Figure $6 \mathrm{C}$ it can be seen that the three thresholds remain about $20 \mathrm{~dB}$ above the spectrum level of noise.

The relationship between the ambient noise level and the thresholds at four frequencies for haddock is shown in Figure 7 . The coefficients of correlation between the thresholds and the noise level are significant at the $0.001-0.05$ levels of probability (Table 4). The threshold data for pollack were inadequate for detailed analysis but a correlation between the thresholds and the noise level was found by combining data for the most sensitive frequencies. The regression line is fitted to these data in Figure 8 and the correlation coefficient is included in Table 4.

The ability of all three species to detect low frequency tones masked by the background noise, approaches the performance of the human ear. The data in Tables 1-3 show that the ratio between the thresholds and the spectrum level of noise at the most sensitive frequencies varies between 14 and $25 \mathrm{~dB}$. These values compare very well with the data for the human ear given by Hawkins \& STEvens (1950). 
Table 4

Relationship between the thresholds and the spectrum level of ambient noise in haddock and pollack

\begin{tabular}{|c|c|c|c|c|c|}
\hline Species & $\begin{array}{l}\text { Frequency } \\
(\mathrm{Hz})\end{array}$ & $\begin{array}{l}\text { Number of } \\
\text { determinations }\end{array}$ & $\begin{array}{l}\text { Slope of } \\
\text { regression } \\
\text { line } \\
\text { (Figs } 7,8)\end{array}$ & $\begin{array}{l}\text { Correlation } \\
\text { coefficient }\end{array}$ & Probability \\
\hline Haddock & $\begin{array}{l}110 \\
200 \\
250 \\
310\end{array}$ & $\begin{array}{r}10 \\
7 \\
6 \\
4\end{array}$ & $\begin{array}{l}0.73 \\
0.85 \\
1.22 \\
1.09\end{array}$ & $\begin{array}{l}0.85 \\
0.87 \\
0.98 \\
0.95\end{array}$ & $\begin{array}{l}<0.01 \\
<0.05 \\
<0.001 \\
<0.05\end{array}$ \\
\hline Pollack & $\begin{array}{l}110 \\
160 \\
310\end{array}$ & 8 & 0.73 & 0.80 & $<0.05$ \\
\hline
\end{tabular}

$\mathbf{x}$

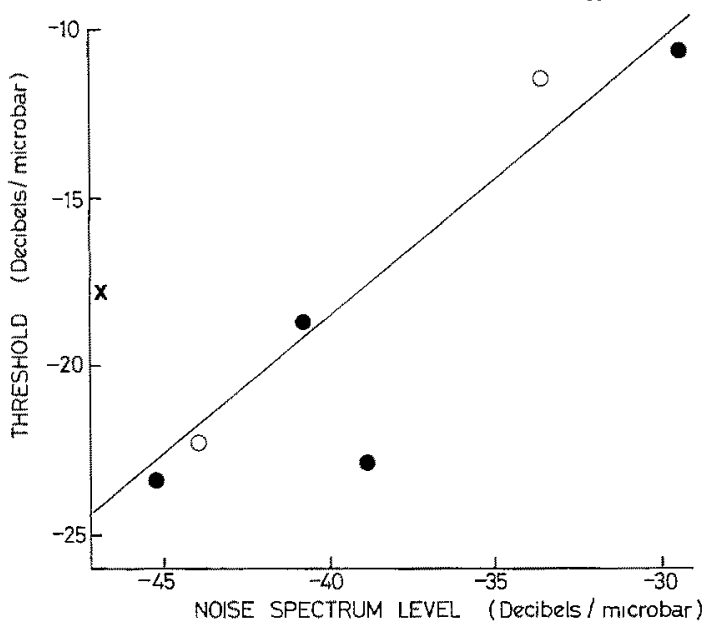

Fig. 8: Relationship between thresholds obtained from pollack and ambient noise level. Combined data for three frequencies, $110(\mathrm{O}), 160(\mathrm{)})$ and $310 \mathrm{~Hz}(\mathrm{x})$

\section{Directional masking}

A number of masking experiments were performed on haddock ( 2 specimens) and cod ( 3 specimens) in which the ability to detect a tone signal was determined in masking noise transmitted from different directions. The fish were first conditioned to the tone against sea noise and then in the presence of masking noise transmitted through the same projector ( $B$ in Fig. 2). The noise level was increased such that the spectrum level was about $20 \mathrm{~dB}$ above the sea noise level. The noise level was held constant whilst the threshold determinations were repeated for the tone transmitted from projectors $A$ and $C$. Figure 9 shows three sequences of threshold determinations obtained in this manner. The thresholds increased in proportion to the noise level 
when the tone and noise sources were the same or $10^{\circ}$ apart, but the thresholds decreased when the angular separation between the tone and noise sources was $85^{\circ}$. Figure $10 \mathrm{~A}$ shows the cardiac response to a tone of $110 \mathrm{~Hz}$ near threshold where the tone and noise were from the same direction. The lower record (Fig. $10 \mathrm{~B}$ ) shows a near threshold response, for the same fish at the same frequency, where the tone and

Table 5

Ratios between the thresholds at different tone frequencies and the spectrum level of transmitted noise for three arrangements of the tone and noise sources. The data in column $0^{\circ}$ were obtained using the same sound projector to transmit both the tone and noise. Particle displacement amplitudes are given for the masked thresholds obtained with $85^{\circ}$ separation of the sound sources

\begin{tabular}{|c|c|c|c|c|c|c|}
\hline Species & \multirow{2}{*}{$\begin{array}{c}\begin{array}{c}\text { Frequency } \\
(\mathrm{Hz})\end{array} \\
40\end{array}$} & \multirow{2}{*}{$\begin{array}{c}\begin{array}{c}\text { Fish } \\
\text { number }\end{array} \\
\text { TC } 1\end{array}$} & \multicolumn{3}{|c|}{$\begin{array}{l}\text { Threshold: noise ratios }(\mathrm{dB}) \text { for } \\
\text { different angular separations } \\
\text { between tone and noise sources } \\
0^{\circ} \quad 10^{\circ} \quad 85^{\circ}\end{array}$} & $\begin{array}{l}\text { Masked threshold } \\
\text { displacement } \\
\text { amplitude } \\
\text { (Ångström units) }\end{array}$ \\
\hline & & & $\begin{array}{l}14.6 \\
18.4\end{array}$ & 16.6 & 11.3 & 8.1 \\
\hline & 110 & TC 1 & $\begin{array}{l}23.5 \\
18.9\end{array}$ & $\begin{array}{l}20.1 \\
26.0\end{array}$ & $\begin{array}{l}13.2 \\
14.7\end{array}$ & $\begin{array}{l}0.61 \\
0.71\end{array}$ \\
\hline & & TC 4 & 28.9 & & & \\
\hline & 200 & TC 32 & 17.5 & 17.7 & $\begin{array}{l}11.4 \\
12.6\end{array}$ & $\begin{array}{l}0.2 \\
0.2\end{array}$ \\
\hline \multirow{7}{*}{ Haddock } & 50 & TH4 & 17.6 & & 12.8 & 5.6 \\
\hline & 110 & TH 3 & 20.1 & 18.9 & 5.9 & 0.2 \\
\hline & & TH 4 & 14.9 & 17.0 & 11.2 & 0.5 \\
\hline & 250 & TH 4 & 23.7 & 20.1 & 16.3 & 0.2 \\
\hline & & & & & 11.4 & 0.1 \\
\hline & 310 & $\mathrm{TH}_{4}$ & 279 & & $\begin{array}{l}13.1 \\
16.3\end{array}$ & $\begin{array}{l}0.2 \\
0.2\end{array}$ \\
\hline & 380 & TH 4 & 21.5 & 24.5 & 15.6 & 0.1 \\
\hline \multirow{5}{*}{\multicolumn{3}{|c|}{$\begin{array}{l}\text { Number of determinations: } \\
\text { Overall means: } \\
\text { Standard error of mean: } \\
\text { Masking level difference: } \\
\text { Probability: }\end{array}$}} & 13 & 8 & 13 & \\
\hline & & & 20.5 & 20.1 & 12.8 & \\
\hline & & & \pm 1.17 & 1.49 & \pm 1.17 & \\
\hline & & & - & $0.4 \quad-$ & 7.7 & \\
\hline & & & Not si & ificant & 0.001 & \\
\hline
\end{tabular}

noise were $85^{\circ}$ apart. The onset of the tone is clearly visible against the filtered noise level in the upper record but the tone is virtually indistinguishable in the lower recording.

The ratios between the thresholds and the spectrum level of masking noise for different sound source arrangements are given in Table 5 which includes data for both haddock and cod at several frequencies. There are no obvious differences in the results for different frequencies. Combining all the data, the results indicate an average improvement in signal detectability of about $7.5 \mathrm{~dB}$ when the tone and noise were $85^{\circ}$ apart. There was no difference in the mean threshold: noise ratios obtained for the same or $10^{\circ}$ separated sound sources. 


\section{DISCUSSION}

\section{Comparison with previous hearing studies in the Gadidae}

There are obvious similarities in the audiograms for haddock, pollack and ling. All three species showed greatest sensitivity at frequencies between 100 and $300 \mathrm{~Hz}$ and a sharp decline in sensitivity at around $400-500 \mathrm{~Hz}$. The fish were insensitive

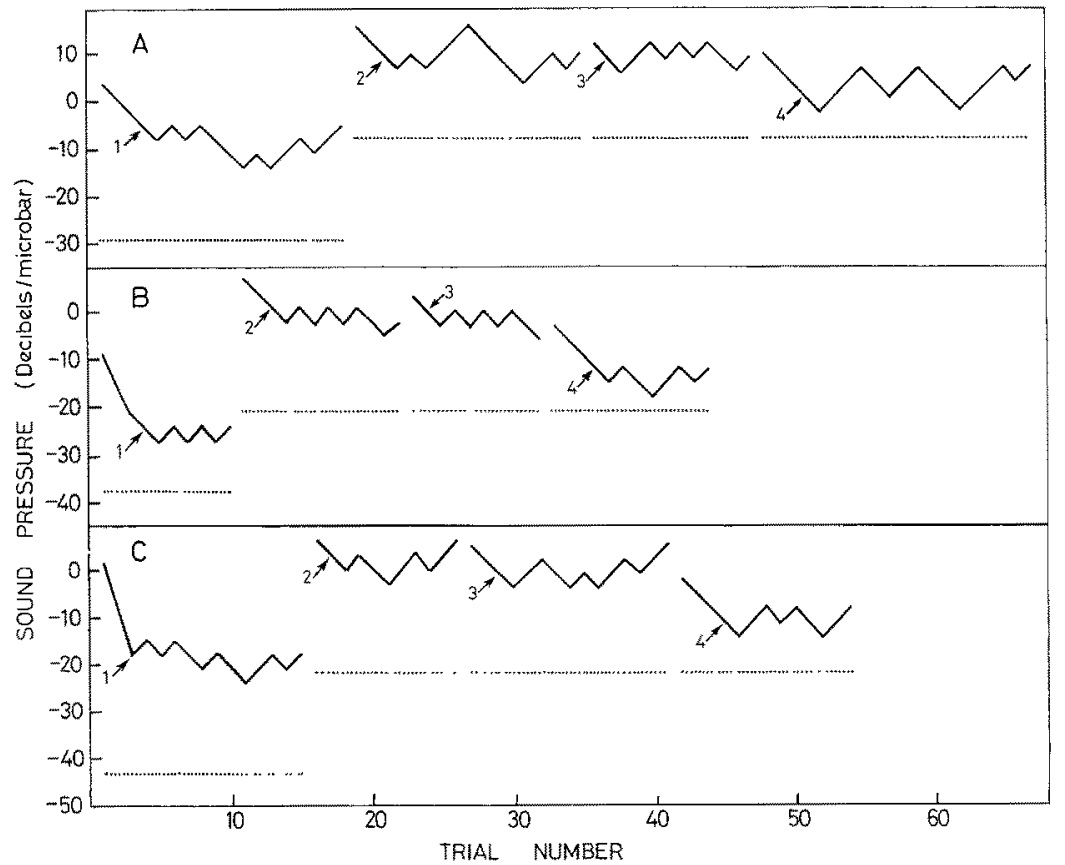

Fig. 9: Threshold determination curves for different directions of masking noise. In each case the sequence of determination was: (1) in the sea noise. (2) in the masking noise from the same sound projector as the tone. (3) tone and noise from different projectors $10^{\circ}$ apart, and (4) tone and noise from projectors $85^{\circ}$ apart. $A$ cod, at tone frequency $40 \mathrm{~Hz} ; B$ haddock, frequency $110 \mathrm{~Hz} ; C$ haddock, frequency $250 \mathrm{~Hz}$. The spectrum level of noise is shown by the dotted lines

to higher frequencies and only the ling gave a reliable threshold at $550 \mathrm{~Hz}$. The hearing curves were very similar to the audiogram for the cod, obtained in a parallel study on the same acoustic range (CHAPMAN \& Hawkrns 1973).

A comparison between hearing data for the cod, obtained by different authors, is given in Figure $11 \mathrm{~A}$ and shows large differences between data obtained under field and laboratory conditions. Threshold measurements in an aquarium were obtained by BUERKLE (1967), using a cardiac conditioning technique, and by OLSEN (1969), using a food-reward conditioning method. Although Buerkle and Olsen found the same upper frequency limit, their thresholds at low frequencies were much higher than the field measurements of Chapman \& Hawkins (1973). BuERKLe (1967) 


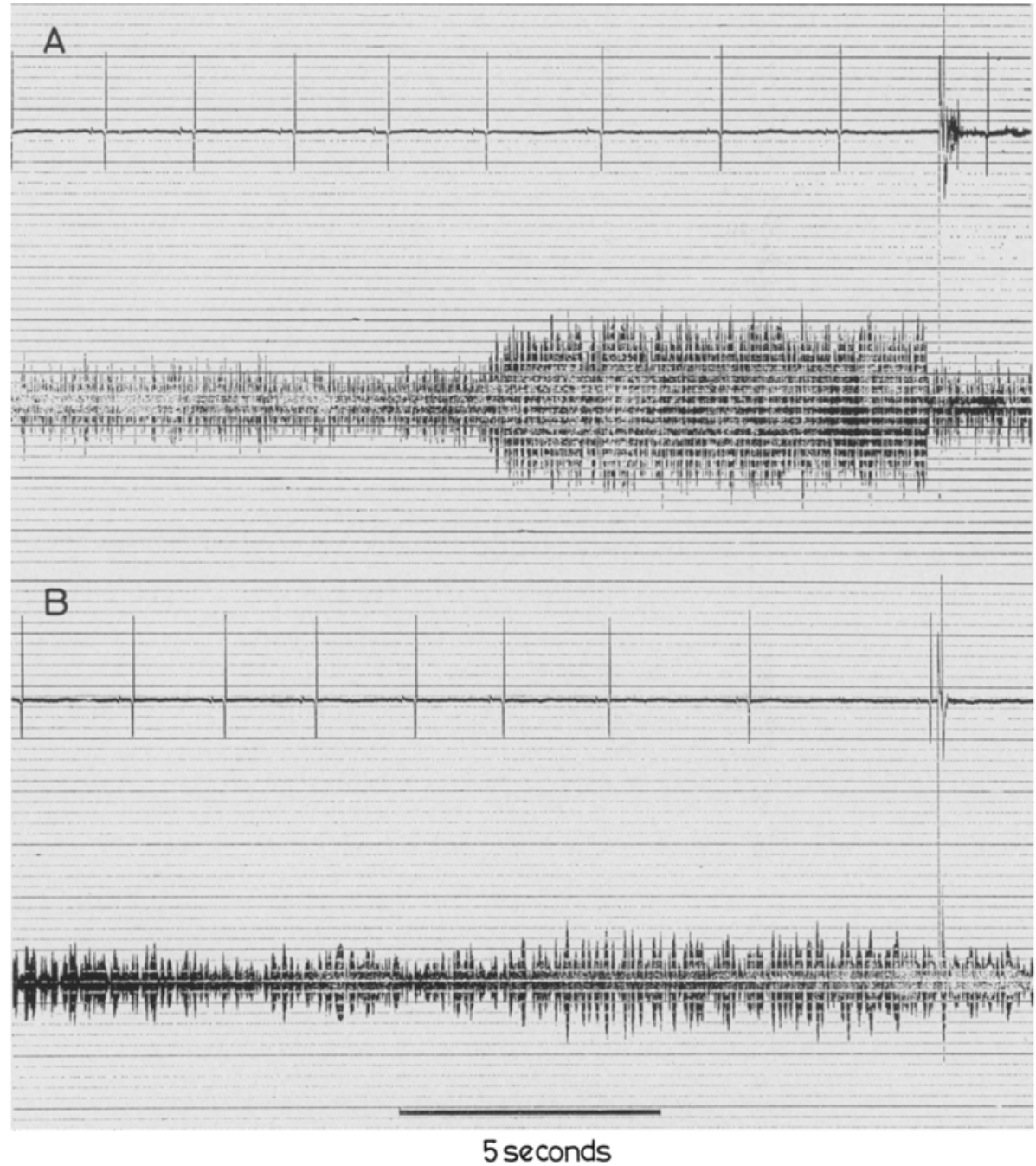

Fig. 10: Cardiac responses to $110 \mathrm{~Hz}$ tone signals just above the threshold level in masking noise. $A$ noise transmitted from same direction as the tone. $B$ noise transmitted from a projector with angular separation of $85^{\circ}$ from the tone source. Note improvement in signal: noise ratio in $B$ where the onset of the sound is virtually indistinguishable in the background noise

showed that cod were sensitive to tones from 18 to $400 \mathrm{~Hz}$ with thresholds varying from -5 to $+18.5 \mathrm{~dB} / \mu$ bar and suggested that the thresholds at low frequencies were masked by the high background noise in the aquarium. This was confirmed in a later study where the noise level in the aquarium was raised artificially (BUERKLE 1968). OLSEN (1969) obtained very high thresholds indeed, varying between -7 and $+25 \mathrm{~dB} / \mu$ bar at frequencies between 50 and $540 \mathrm{~Hz}$. These thresholds were probably masked by a very high aquarium noise level. OLsen tested sound sources at two 


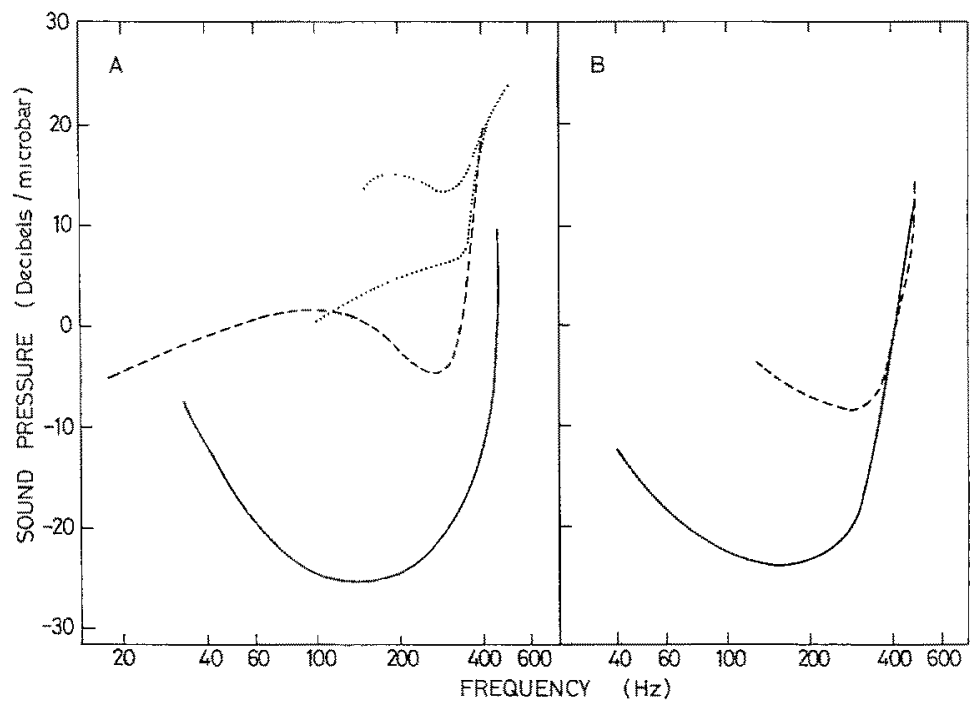

Fig. 11: Comparison between hearing data in Gadidae obtained by different authors. $A$ cod: after Chapman \& Hawkins (1973); - - after Buerkle (1967); $\cdots \cdots$ after Olsen (1969). $B$ pollack: - from Figure 4 of this paper; - - - after CHAPMAN \& Hawkins (1969)

distances from the fish and reported differences in the sound pressure thresholds (shown by two dotted curves in Fig. $11 \mathrm{~A}$ ) at frequencies as high as $350 \mathrm{~Hz}$ and it is doubtful whether the fish were responding to the sound pressure component. On the other hand, CHAPMAN \& HAwKINs (1973) suggested that cod in their natural environment were sensitive to acoustic pressure at all frequencies but they obtained some evidence for displacement sensitivity at low frequencies (below $50 \mathrm{~Hz}$ ) when the sound source was within $1 \mathrm{~m}$ of the fish.

Field and laboratory audiograms for the pollack are compared in Figure $11 \mathrm{~B}$. The laboratory study was carried out using an avoidance conditioning technique (CHAPMAN \& HAWKINS 1969). As in the cod, there is good agreement in the data at high frequencies. The results of the present study show that in the low ambient noise level of a calm sea, the hearing of pollack at their most sensitive frequencies is about 10-20 dB better than the figures given by ChapMan \& Hawkins (1969). It seems likely that the higher thresholds were masked by the aquarium noise level.

The frequency range of hearing in members of the Gadidae is evidently smaller than for most other species that have been studied (see recent reviews by TAvolgA 1965,1972 ). Sensitivity in marine teleosts generally extends to at least $1000 \mathrm{~Hz}$ and in the largely freshwater Ostariophysi, hearing extends as high as $5000 \mathrm{~Hz}$. Sensitivity to sounds up to $1000 \mathrm{~Hz}$ has been demonstrated in the elasmobranch fishes such as the shark, Negaprion brevirostris (NELSON 1967). TAvolgA \& WonINsKY (1963) obtained hearing data for several North American marine species representing different families and reported upper frequency limits to hearing between 1000 and $2400 \mathrm{~Hz}$. Maximum sensitivities were found in the range from 200 to $800 \mathrm{~Hz}$ but the thresholds varied from -40 to $+15 \mathrm{~dB} / \mu$ bar in different species (see below). 
Previous attempts to study the hearing of fish under field conditions have been reported (ENGER \& ANDERSEN 1967, Fish \& OfFUTT 1972) but only at relatively shallow depths. ENGER \& ANDERSEN compared the hearing of the cod and the sculpin, Cottus scorpius (= Myxocephalus scorpius [L.]) by recording microphonic potentials from the labyrinth of the fish. They varied the sound source distance and suggested that hearing in the sculpin was limited to the near-field of the sound source whereas the cod could detect sounds at greater distances. Since the sculpin has no swimbladder, these differences were attributed to the accessory role of the swimbladder in the hearing of cod. In the paper by FisH \& OfFuTt (1972), hearing thresholds from the toadfish, Opsanus tau, obtained under laboratory and field conditions were compared. No differences were found in the thresholds obtained by cardiac conditioning experiments in the laboratory and by observing the effects of pure tone transmission on sound production of the toadfish in the field. The lowest thresholds were at frequencies between 37.5 and $150 \mathrm{~Hz}$ where the sound pressure was about $1 \mu$ bar. In the field determinations the tone threshold at $100 \mathrm{~Hz}$ was less than $8 \mathrm{~dB}$ above the ambient noise level in the octave band, $75-150 \mathrm{~Hz}$. This corresponds to a threshold: noise ratio of about $27 \mathrm{~dB}$. Comparison with the values of threshold: noise ratio presented in this paper (Tables 1-3) suggests that the toadfish thresholds may have been masked by the ambient noise level, even though they were based on unconditioned responses.

\section{Hearing and ambient sea noise}

Hearing in the haddock, pollack and ling was clearly affected by the ambient noise level. It was evident during conditioning that any change in noise level produced a corresponding shift in the thresholds (Fig. 6). In haddock, where the data were sufficient for a detailed analysis, there was a direct correlation between the thresholds and the spectrum level of sea noise (Fig. 7). The results presented in this paper are very similar to those reported for the cod by Chapman \& Hawnins (1973). The cod study was based on a very large number of thresholds obtained at different sea states and noise levels. The results showed that masking was negligible in calm sea conditions (sea state 0 ) but masking occurred at higher sea states due to the increased background noise level. This suggests that the hearing of cod is very well matched to ambient noise levels in the environment and, from the present study, this appears to be true for haddock, pollack and ling. The audiograms all show a similar shape to the noise spectrum curve at frequencies below the cut-off frequency, with a decrease in sensitivity at low frequencies corresponding to the higher noise level below $100 \mathrm{~Hz}$. This decline in sensitivity at low frequencies is a common feature of the audiograms for most species.

Although a similarity in hearing ability might be expected in closely related species, the demonstration of a relationship between hearing and the level of ambient sea noise in four gadoid species suggests that a similar relationship may be found in a great number of other species. It might be expected that there would be much more similarity between the hearing of different species occupying the same habitat (and therefore the same conditions of ambient noise). Apart from the present work, the 
only systematic study of several species from the same area is that of TAvolgA \& WODINSKY (1963), already mentioned. These authors reported a $60 \mathrm{~dB}$ variation of sensitivity in nine species occupying the same habitat. These measurements were obtained in an aquarium under rather anomalous acoustic conditions, where the fish may well have been responding to the particle displacement component of the sound rather than to the acoustic pressure wave. This would account for the large changes in threshold which appeared in some of the species tested by TAvolga \& WoDINSKY after repeated testing at low frequencies over a period of several days.

\section{Directional hearing}

The ability of fish to detect low frequency sounds in their natural environment is very well developed and it is clear that fish can detect sounds over great distances. This would seem to provide the fish with an immense amount of information of little or no value unless the sources of sound could be located. There is surprisingly little information on the ability of fish to determine the direction of a sound source or to discriminate between sounds from different directions. Most of the earlier literature on this question has been discussed by VAN BERGEIJK (1964) in relation to the physical requirements for directional hearing in fish. He suggested that localisation would only be possible very close to the sound source (within the near-field) where the gradient of particle displacement would be very steep and the source could be located by means of the lateral-line system. VAN BERGEIJK pointed to the role of the swimbladder in farfield hearing (see also CHAPMAN \& HAwKINS 1973) and showed that a single pressure receptor was inadequate for directional hearing. Even in the absence of a swimbladder, he also suggested that the acoustic properties and dimensions of the fish's head, in relation to low frequency sounds, would preclude localisation through binaural intensity and time differences in the labyrinth. On the other hand, a great deal of information has recently been published on the orientation of sharks, and other predatory fish, to low frequency sounds over considerable distances in their natural environment (for example, Myrberg et al. 1969, NELSON \& JoHnson 1972).

The experiments on the masking effect of noise presented in this paper show that masking is reduced by several decibels when the tone and noise are from different directions, suggesting that directional discrimination may be well developed in fish such as cod and haddock. No comparable studies on fish have been published before but several papers deal with the phenomenon of binaural and monaural masking in the case of the human ear. HIRsH (1948), for example, found that in the presence of masking noise in both ears, the detection of a low frequency tone presented to one ear was about $7 \mathrm{~dB}$ better than when the tone was presented to both ears. These experiments have since been repeated many times in one form or another and various theories have been put forward to account for the results (e.g. JefFress et al. 1956, DURLACH 1963). The improvement in signal detectability appears to depend on binaural differences in the phase of the masking noise and signal tone. It is interesting to find similar masking level differences in fish where the existence of binaural hearing is in doubt. In the absence of more detailed knowledge of directional hearing in fish, it is difficult to account for these results. 
The particle displacement amplitudes corresponding to the masked thresholds obtained with the tone and noise sources $85^{\circ}$ apart are given in Table 5. These values were calculated from the wave equations given by HARRIs (1964). With the exception of the thresholds at 40 and $50 \mathrm{~Hz}$, for which the fish were within the near-field of the sound source, all the displacements were less than $1 \AA \AA$. These values are well below thresholds for the lateral-line organ of about $25 \AA$, given by KuIPER (1956). On the other hand, these values fall within the range of hearing thresholds obtained for two species of flatish, Pleuronectes platessa and Limanda limanda (SAND \&. CHAPMAN unpublished). Neither of these species possesses a swimbladder in adult life and by varying the sound source distance, these fish were found to be sensitive to the particle motion component of the sound at frequencies between 30 and $250 \mathrm{~Hz}$. These thresholds were attributed to detection of the sound by the paired otolith organs in the labyrinth. From the work of WERSÄLL et al. (1966) on the orientation of the hair cells in the labyrinth of the burbot, Lota vulgaris, it seems likely that the response amplitude in the hair cells might be different according to their direction and this could offer a basis for sound location. In fish which possess a swimbladder, however, it is not clear whether the paired otoliths would be sensitive to the particle displacements associated with the direct sound wave as well as to the volume displacements radiated from the swimbladder. There is at least some evidence that the otolith organs may be stimulated in both ways from work on cod (CHAPMAN \& Hawkins 1973) but it remains to be established whether the labyrinth functions in directional hearing.

\section{SUMMARY}

1. Field measurements of hearing in haddock, Melanogrammus aeglefinus, pollack, Pollachius pollachius and ling, Molva molva, show that they are sensitive to sounds in the frequency range from 30 to $500 \mathrm{~Hz}$, with greatest sensitivity from 100 to $300 \mathrm{~Hz}$.

2. At the most sensitive frequencies the thresholds varied between -15 to $-25 \mathrm{~dB}$ relative to a sound pressure of $1 \mu \mathrm{bar}$.

3. In all three species, the thresholds at some frequencies were affected by the level of ambient sea noise. A direct correlation between the thresholds and the spectrum level of sea noise was obtained in haddock and pollack.

4. The masking effect of sea noise was confirmed in some experiments on cod, Gadus morbua and haddock, where the background noise level was raised artificially. It was found that the masking of a tone signal was reduced by about $8 \mathrm{~dB}$ when the tone and noise were from different directions ( $85^{\circ}$ apart), suggesting that directional discrimination may be well developed in these fish.

Acknowledgments. I would like to thank Mr. B. B. PARrish for encouragement and for commenting upon the manuscript. Advice and technical assistance was gratefully received from B. S. MCCARTNey and A. R. Stubes (National Institute of Oceanography) and from my colleagues, A. D. Hawrins, J. Marn, D. N. Maclennan, W. Hald and S. T. Forbes. Special thanks are due to A.D. F. JoHnstone, G. R. PARK, C. RoBB and other members of the Marine Laboratory diving tean who took part in the field work. 


\section{LITERATURE CITED}

BERGEIJK, W. A. van, 1964. Directional and nondirectional hearing in fish. In: Marine bioacoustics. Ed. by W. N. Tavolga, Pergamon Press, Oxford, 1, 281-299.

Brawn, V. M., 1961. Sound production by the cod (Gadus callarias L.). Behaviour 18, 239-255.

Buerkle, U., 1967. An audiogram of the Atlantic cod, Gadus morbua L. J. Fish. Res. Bd Can. 24, 2309-2319.

- 1968. Relation of pure tone thresholds to background noise level in the Atlantic cod (Gadus morhua). J. Fish. Res. Bd Can. 25, 1155-1160.

Chapman, C. J. \& Hawkins, A. D., 1969. The importance of sound in fish behaviour in relation to capture by trawls. Fish. Rep. F.A.O. 62 (3), 717-729.

- 1970a. Field studies of hearing in cod. Proc. Challenger Soc. 4, 59-60.

- 1970b. Further studies on hearing in teleost fish. Proc. Challenger Soc. 4, 90-91.

- 1973. A field study of hearing in the cod, Gadus morbua L. (In preparation).

Dixon, W. J., 1965. The up and down method for small samples. J. Am. statist. Ass. 60, 967-978.

DURLACH, N. I., 1963. Equalization and cancellation theory of binaural masking-level differences. J. acoust. Soc. Am. 35, 1206-1218.

Enger, P. S. \& Andersen, R., 1967. An electrophysiological field study of hearing in fish. Comp. Biochem. Physiol. 22, 517-525.

Fish, J. F. \& OffutT, G. C., 1972. Hearing thresholds from toadfish, Opsanus tau, measured in the laboratory and field. J. acoust. Soc. Am. 51, 1318-1321.

Grifrin, D. R., 1950. Underwater sounds and the orientation of marine animals, a preliminary survey. Tech. Rep. (ONR and Cornell Univ.) 3.

Harris, G. G., 1964. Considerations on the physics of sound production by fishes. In: Marine bioacoustics. Ed. by W. N. Tavolga, Pergamon Press, Oxford 1, 233-247.

- \& BeRgeijK, W. A. van, 1962. Evidence that the lateral-line organ responds to near field displacements of sound sources in water. J. acoust. Soc. Am. 34, 1831-1841.

Hawkins, A. D. \& Chapman, C. J., 1966. Underwater sounds of the haddock, Melanogrammus aeglefinus. J. mar. biol. Ass. U. K. 46, 241-247.

- — S Symonds, D. J., 1967. Spawning of haddock in captivity. Nature, Lond. 215, 923-925.

Hawkins, J. E. \& Stevens, S. S., 1950. The masking of pure tones and of speech by white noise. J. acoust. Soc. Am. 22, 6-13.

HrRsh, I. J., 1948. Binaural summation and interaural inhibition as a function of the level of masking noise. Am. J. Psychol. 61, 205-213.

Jacobs, D. W. \& Tavolga, W. N., 1967. Acoustic intensity limens in the goldfish. Anim. Behav. 15, 324-335.

Jeffress, L. A., Blodgett, H. C., Sandel, T. T. \& Wood, C. L., 1956. Masking of tonal signals. J. acoust. Soc. Am. 28, 416-426.

Kuiper, J. W., 1956. The microphonic effect of the lateral-line organ. Biophys. Group, Natuurkundig Lab., Groningen, 159 pp.

MYBerg, A. A., BANNER, A. \& Richard, J. D., 1969. Shark attraction using a video-acoustic system. Mar. Biol. 2, 264-276.

NeLson, D. R, 1967. Hearing thresholds, frequency discrimination and acoustic orientation in the lemon shark, Negaprion brevirostris (POEY). Bull. mar. Sci. 17, 741-768.

- \& Johnson, R. H., 1972. Acoustic attraction of Pacific reef sharks: Effect of pulse intermittency and variability. Comp. Biochem. Physiol. (A) 42, 85-95.

OLSEN, K., 1969. A comparison of acoustic threshold in cod with recordings of ship noise. Fish. Rep. F.A.O, 62 (2), 431-438.

Parvulescu, A., 1964. Problems of propagation and processing. In: Marine bioacoustics, Ed. by W. N. Tavolga. Pergamon Press, Oxford 1,87-100. 
- 1967. The acoustics of small tanks. In: Marine bioacoustics. Ed. by W. N. TAvolga. Pergamon Press, Oxford 2, 7-8.

Poggendorf, D., 1952. Die absoluten Hörschwellen des Zwergwelses (Ameiurus nebulosus) und Beiträge zur Physik des Weberschen Apparatus der Ostariophysen. Z. vergl. Physiol. 34, 222-257.

TAvolga, W. N., 1965. Review of marine bio-acoustics. Tech. Rep. (U.S. Naval Training Device Center). NAVTRADEVCEN 1212-1, $100 \mathrm{pp}$.

- 1972. Sound production and detection. In: Fish physiology. Ed. by W. S. Hoar \& D. J. Randall. Acad. Press, New York 5, 135-205.

- \& Wonrnskx, J., 1963. Auditory capacities in fishes. Pure tone thresholds in nine species of marine teleosts. Bull. Am. Mus. nat. Hist. 126, 179-239.

WersätL, J., FLOCK, A. \& Lundquist, P. G., 1966. Structural basis of directional sensitivity in cochlear and vestibular sensory receptors. Cold Spring Harb. Symp. quant. Biol. 30, $115-132$.

Author's address: C. J. Chapman

Marine Laboratory

Victoria Road

Aberdeen AB9 8DB

Scotland 